Удк 94(33)

ББК 63.3(0)32

\title{
Брачные запреты
}

\section{в династической политике Хасмонеев}

\section{Михаил Николаевич Каранаев}

(Нижнекамский химико-технологический институт, Нижнекамск, Россия)

Кандидат исторических наук, ORCID ID : 0000-0001-9342-7078, доцент, кафедра государственного и муниципального управления, социологии и менеджмента Нижнекамского химико-технологического института (филиал) федерального государственного бюджетного образовательного учреждения высшего образования «Казанский национальный исследовательский технологический университет», 423578, Республика Татарстан, г. Нижнекамск, пр. Строителей, 47, тел.: +7 (8555) 39-23-87,

E-mail: karanaevmk@mail.ru

DOI: $10.31168 / 2658-3356.2018 .4$

Аннотация: В статье рассказывается о брачных запретах в династической политике государства Хасмонеев (II-I вв. до н.э.). Иудейские правители очень строго подходили к процессу выбора партнера. Главными критериями была ритуальная чистота и хорошее происхождение (с точки зрения норм иудаизма), а также принадлежность к иудейской элите. При последних правителях независимого государства Хасмонеев (Аристобул II и Гиркан II) происходит переход к кровнородственным бракам. Одной из причин является влияние эллинистической традиции, в которой подобные браки нормальны. При этом в иудаизме есть запреты на инцест, но Хасмонеи смогли соответствовать нормам иудаизма (брак с двоюродной сестрой). Подобная политика служит прекрасным примером специфики династии Хасмонеев: следовать нормам иудаизма, при этом быть в контексте общеэллинистической парадигмы.

Ключевые слова: Иудея, иудаизм, государство Хасмонеев, эллинизм, брачные запреть

Государство Хасмонеев, существовавшее во II-I вв. до н.э., являет собой интереснейший пример кросскультурного взаимодействия иудейской и эллинистической традиций. Одним из явлений, демон-

Материалы собраны благодаря программе Центра «Сэфер» по поддержке исследований в области иудаики (грант Genesis Philantrophy Group). 
стрирующих специфику этих контактов, служит династическая политика хасмонейских правителей. В силу причастности к роду первосвященников, а также в связи с предпосылками к восстанию Маккавеев (конфликт на почве чрезмерного проникновения эллинистических норм в Иудею) они были вынуждены соблюдать нормы иудаизма. Но при этом мы можем наблюдать, как по мере становления хасмонейского государства в нем все более активно набирали силу явления, берущие свою основу именно в эллинистической культуре.

Брачные запреты в иудейской традиции - тема, которую сложно назвать малоизученной. Причиной тому служит огромный (по сравнению со многими иными проблемами иудейской истории) массив данных нарративных источников. Информацию о брачных запретах можно найти как в отдельных главах Танаха (Втор 27:20-22; Лев 18:6-18 и др.) ${ }^{1}$, так и в Мишне. Что касается последней, то в трактате «Иевамот» существует специальный раздел, описывающий брачные запреты. В связи с этим нет необходимости разбирать все нюансы социальной и идеологической природы некоторых ограничений в брачном законодательстве ${ }^{2}$.

Если попытаться обобщить все имеющиеся сведения, касающиеся брачных запретов, то можно выделить две основные причины, их порождающие: различие в социально-правовом статусе и родственная связь вступающих в брачные отношения. Оба ключевых запрета вполне применимы к ситуации вокруг брачной политики династии Хасмонеев, и их изучение позволяет уточнить имеющиеся лакуны, например в том, что касается неизвестных нам женщин, на которых были женаты правители из династии Хасмонеев. Не менее важна, впрочем, оценка эллинистического влияния на правителей периода независимого государства Хасмонеев.

Один из наиболее известных исследователей истории еврейского брака Михаэль Сатлоу в своей работе «Jewish Marriage in Antiquity»

${ }^{1}$ Сведения о брачных запретах в Танахе рассеяны по всему тексту, не систематизированы и иллюстрируют отдельные бытовые эпизоды, в контексте которых и присутствует интересная для нашего исследования информация. См.: Григер 2008, 31.

${ }^{2}$ Среди отечественных исследователей эту проблему детально изучил в своей диссертации М.В. Григер, посвятивший отдельный параграф брачным запретам. В работе казанского историка, оказавшего значительное влияние на наше исследование, изучается социальная и идеологическая основа ряда ограничений в брачном законодательстве таннаев с обзором предшествующей исторической традиции. Там же можно ознакомиться с основной библиографией по проблеме, см.: Григер 2008, 54-70. 
выделил три посыла, касающихся брачных союзов. Во-первых, понимание функций, целей и формы брака зависело от конкретной локальной группы иудеев (как пример приводятся палестинские и вавилонские евреи) [Satlow 2001, 61, 190]. Во-вторых, в античную эпоху сложно выделить что-то «специфически еврейское в еврейском браке». Даже с учетом того, что нормы иудейской традиции были довольно сильны и их старались придерживаться хотя бы внешне, на практике браки сильно зависели от исторического и регионального контекста. Зачастую они больше вбирали от соседей, нежели от общих норм иудаизма. Третий посыл М. Сатлова исходит из уже озвученных и суммирует их: браки, заключаемые иудеями, в реальности были далеки от идеальных норм, описанных в священных текстах [Григер 2008, 21; Satlow 2001].

Все эти тезисы нуждаются в серьезном уточнении, когда мы говорим об элите иудейского общества в период династии Хасмонеев, который пришелся на пик проникновения эллинистической культуры в Восточное Средиземноморье. Кроме того, следует учитывать, что сами Хасмонеи относились к роду первосвященников, поэтому для них следование нормам традиции было принципиально важным. Однако нельзя сбрасывать со счетов эллинистический контекст.

Если мы возьмем за образец для сравнения малоазийские малые монархии эллинистического мира как наиболее показательные в этногеографическом и политическом отношениях, то увидим интересную ситуацию ${ }^{3}$. Формирование правящего слоя в Иудее до восстания Маккавеев несколько отличается от малоазийского варианта прежде всего именно в силу специфики этнорелигиозных традиций. Формирование малоазийского этнокласса носит региональный характер, когда между представителями местных элит разных частей Малой Азии еще с V-IV вв. до н.э. устанавливаются брачно-дина-

${ }^{3}$ При оценке малых монархий эллинистического мира, к коим, без сомнения, можно отнести и Иудею хасмонейского периода, наиболее логично проводить аналогию именно с малоазийскими государствами. Даже с учетом множества лакун в их истории, они являются наиболее изученными среди прочих на сегодняшний день. Также это обусловлено некоторой географической отчужденностью Иудеи от других малых монархий, активным взаимодействием с государством Селевкидов, а также нахождением прежде в составе Ахеменидской империи [Каранаев 2015, 43]. Дж. Ма пишет, что малые государства Востока, возглавляемые негреками (в том числе и государство Хасмонеев), проводили целенаправленную политику эллинизации и стремились подражать монархам великих эллинистических держав [Ма 2004, 254-255]. 
стические связи [Габелко 2006, 83-85], в то время как династическая политика правящих домов Иудеи, начиная с эпохи Эзры и Неемии, носит преимущественно внутреннюю направленность.

В Иудее дохасмонейского периода долгое время ключевую роль играла династия Товиадов, первое упоминание о которой относится к VIII в. до н.э. (Ис 7:6) ${ }^{4}$. На протяжении нескольких столетий род Товиадов играл заметную роль в управлении Иудеей ${ }^{5}$. Источники не изобилуют информацией о династических браках между представителями влиятельных родов в Иудее, однако мы имеем упоминание Иосифа Флавия о браке между представителями семей Товиадов и Ониадов (AJ XII:4,2). Этот брак наглядно показывает нам, что ведущий род Иудеи придерживался осторожной брачной политики и роднился с представителями той же этногруппы. Сложно предположить, чтобы семья первосвященника Онии породнилась с кем-то, чистота чьей крови могла вызывать хоть какие-то сомнения. Даже с учетом проэллинистической политики, проводимой обоими домами, их принадлежность к евреям и иудаизму представляется несомненной. Подтверждением чему служит Вторая книга Маккавеев, которая, несмотря на всю антиэллинистическую риторику и благочестивый тон, признает за Онией III «тщательное соблюдение законов» и особую духовность (2 Мак 3:1, 31-35; 4:1, 38). Высказывая сомнения в еврейском происхождении Иосифа, сына Товии (по причине активной эллинизаторской деятельности), еще С. Цейтлин, апеллируя к Иосифу Флавию и Маккавейским книгам, достаточно убедительно обосновывает обратное [Zeitlin 1932-1933, 215-219].

Учитывая связи Товиадов и Ониадов за пределами Иудеи (в государстве Птолемеев прежде всего) ${ }^{6}$, следует предполагать осуществление брачной политики по тому же принципу, не выходя из одной

${ }^{4}$ В частности, Товиады сыграли заметную роль в попытке смещения царя Ахаза, а также имеются упоминания о них в Лахишских остраконах, датируемых 588 г. до н.э. [Mazar 1957, 137-145; Noegel 2006, 400-403].

${ }^{5}$ Роду Товиадов посвящено немало исследований, поэтому мы не планируем заострять на них внимание, поскольку в государстве Хасмонеев они заметной роли не играли; последнее упоминание о них относится к 165/4 г. до н.э. (2 Мак 12:17) [Gera 1990, 21-38; Schwartz 2002, 146-151].

${ }^{6}$ В этой связи особенно интересно, что в Египте эпохи Птолемеев существовали иные, отличные от «общечеловеческой» этики, представления об инцесте [Григер 2008, 55]. 
этногруппы, благо еврейская диаспора была достаточно расселена по региону.

Таким образом, системы родственных связей внутри правящего слоя Иудеи формировались в течение очень долгого времени и продолжали функционировать даже в кардинально изменившихся исторических условиях. Приход к власти Хасмонеев первоначально не несет в себе принципиального изменения в брачной политике правящего слоя. Хасмонеи продолжают практику браков с представителями местной знати [Ilan 1995, 1-33].

Источники по вопросу брачной политики правящей династии не блещут разнообразием, однако мы имеем данные о зяте Симона, предпринявшем попытку переворота, в результате которого Симон и два его сына погибают:

Птолемей же, сын Авува, поставлен был военачальником на равнине Иерихонской и имел много серебра и золота; ибо он был зять первосвященника (1 Макк 15:11-12).

Из приведенного фрагмента мы можем видеть, что Птолемей имеет явное еврейское происхождение, во-первых, исходя из имени отца, а во-вторых, по все тем же принципам сохранения чистоты крови первосвященнического рода, с которым себя соотносили Хасмонеи. Также несомненной представляется принадлежность Птолемея, сына Авува, к числу иудейской аристократии, доказательством чего служит его попытка узурпации власти. Сложно представить, чтобы на это решился человек, не имеющий определенного веса в обществе [Каранаев 2015, 46-47]. Да и в целом, даже учитывая то, что брачные запреты, связанные с социально-правовым статусом жениха и невесты, носят менее универсальный и табуированный характер, стремление к заключению брачного союза с представителями своей социальной группы не представляется нуждающимся в оспаривании. Тем более, как довольно четко описал М.В. Григер, впоследствии в трактате «Кидушин» таннаи пошли далеко за пределы библейских представлений, выработав совершенно новые термины и правила, в том числе определив особые брачные касты. Браки между некоторыми кастами были запрещены, а их совершение наказывалось понижением статуса потомства. Формально эти касты были связаны с понятием религиозной чистоты, и в этом можно увидеть идеологию «сакрализации» жизни еврейского социума. Однако за 
разработкой рабби понятий генеалогической чистоты можно увидеть их попытку утвердить свою власть в обществе, а также некоторые предрассудки о «плохой крови» (например, вольноотпущенников), характерные в целом для общества как эллинистического, так и Римской империи [Григер 2008, 64-66].

Кроме примера с зятем Симона, существуют отрывочные сведения о женах всех правителей хасмонейской Иудеи. Однако мы не обладаем информацией об их происхождении, что, в свою очередь, косвенно подтверждает их «внутрииудейское происхождение», поскольку если бы речь шла о внешних династических союзах, то Иосиф Флавий не мог об этом не упомянуть. Нельзя не отметить, что проблема генеалогии Хасмонеев в целом и ее женской части в частности недостаточно освещена. Преимущественное внимание исследователей направлено на Александру Саломею, что вполне закономерно, учитывая ее статус и роль в еврейской истории (АJ XIII:10-11) [Ilan 2001, 57-68].

Жена Аристобула I, будущая правительница Александра Саломея, ведет свою собственную придворную политику, вероятным следствием которой становится гибель Аристобула I от болезни (АJ XIII:11,3). После этого Саломея, согласно правилам левиратного брака (Втор 25:5-9), становится женой Александра Янная. И конец ее правления, и смерть от болезни омрачены начавшейся гражданской войной между сыновьями Саломеи Аристобулом II и Гирканом II (AJ XIII: $16,4-6)^{7}$.

При последних независимых правителях Иудеи брачная политика Хасмонеев приобретает черты, не совсем обычные для иудейской традиции, но вполне характерные для эллинистических государств. Речь идет о кровнородственных браках. Мы имеем сведения о том,

${ }^{7}$ Существует гипотеза, что жена Янная Александра Саломея не была женой Аристобула I, которую, в свою очередь, звали Салина Александра [Ilan 2006, 47; Atkinson 2008, 62-65, 72]. Эта версия не представляется достаточно убедительной не только по причине слабодоказуемых аргументов, базирующихся на более поздних раввинистических источниках, но и по причине четкого соотнесения с книгой Второзакония, где говорится о наречении первенца (Аристобула II) от брака с Александром Яннаем в честь Иуды Аристобула I (Втор 25:6). Довод о том, что Саломея была вдовой и поэтому не могла стать женой первосвященника, также стоит подвергнуть критике в силу того исторического контекста, в котором проходила процедура передачи власти после смерти Аристобула I (Александр Яннай вместе с братьями был заточен в тюрьме), и деятельности придворного общества, возглавляемого Саломеей. 
что Аристобул II был женат на своей двоюродной сестре, дочери Апсалома, который приходился братом его отцу Александру Яннаю $(\mathrm{AJ} X \mathrm{XIV}: 4,4)^{8}$. А сын Аристобула II Александр был женат на дочери Гиркана II (AJ XIV:14,5) ${ }^{9}$. Подобная практика весьма необычна даже в контексте левиратного брака Саломеи, но тем не менее не противоречит иудейской традиции, соблюдение которой особенно важно для рода первосвященника.

Если более детально обратиться к иудаизму Второго Храма, то в Мишне, в частности в трактате «Иевамот», в котором собраны положения, касающиеся брачных запретов, мы не найдем прямого запрета на брак с двоюродными сестрами (М. Иев. 1:1), несмотря на довольно детальный перечень запретных контактов. Не найдем мы его и в книге Левит, где также содержатся сведения о брачных запретах (Лев 18:16-17). Вместе с тем довольно интересно, что представление о табу на связь с некоторыми кровными родственниками прослеживается в библейском материале и других древних законодательствах. Впоследствии в эпоху Мишны таннаи расширили список этих запретов (М. Иев. 2:4), что, вероятнее всего, связано с их общей привязанностью к упорядочиванию, нежели эти запреты имели действительно важное практическое значение [Григер 2008, 54; Moor 1932, 121]. Нельзя не обратить внимания, что тексты Мишны, посвященные вопросу брака, зачастую имеют метафорический смысл, это отмечают А.Б. Ковельман и У. Гершович в отношении трактата «Киддушин» [Ковельман, Гершович 2014, 12]. Подобное затрудняет не только трактовку текста, но и осмысление реальности применения некоторых фрагментов, описанных в текстах Мишны.

Тем не менее нельзя утверждать, что близкородственные браки стали обыденностью в последующей еврейской традиции.

8 «...Также и Апсалом, дядя и тесть Аристобула, попал при этом случае в плен» (AJ XIV:4,4).

9 «Так ревностно соблюдал Антоний интересы Ирода, что не только выхлопотал ему, не рассчитывавшему вовсе на это, царскую власть, но и добился того, чего уже никак не ожидал Ирод, что он мог в качестве царя выехать спустя семь дней из Италии (дело в том, что Ирод хотел домогаться царского достоинства не для себя лично, так как не рассчитывал на это, потому что римляне имели обыкновение провозглашать царями лишь лиц соответствующего происхождения, а для своего шурина Аристобула, который был внуком Аристобула со стороны отца и внуком Гиркана по матери). Этого молодого человека Ирод, впрочем, казнил, как мы покажем в свое время» (AJ XIV:14,5). 
Говоря о причинах, побудивших Хасмонеев перейти к родственным бракам, кроме уже заявленной причины сохранения чистоты крови, следует рассмотреть и эллинистические мотивы, способствующие заключению подобного брака. Если мы обратимся к истории Селевкидов или малоазийских монархий, то увидим, что браки между близкими родственниками - это достаточно распространенное явление [Seibert 1967, 129-131], основа которого, впрочем, лежит не только и не столько в государстве Селевкидов и общеэллинистическом контексте. Вполне вероятно, здесь имело место влияние со стороны Ахеменидов, которое Д. Огден склонен видеть в восприятии практики кровнородственных браков Селевкидами [Ogden 1999, 125-127]. Но, вероятно, именно Селевкиды стали проводником этой традиции в Иудею (к сожалению, источники об Иудее ахеменидского периода еще более скудны).

Даже с учетом неясности происхождения жены Иоханана Гиркана и родовой принадлежности Александры Саломеи соотнесение с эллинистической традицией в браках Аристобула II и его сына Александра не вызывает особых сомнений. Правда, делать однозначный вывод о том, что эти браки являются исключительно следствием восприятия эллинистической культуры, конечно же, чрезмерно опрометчиво. Разумеется, прослеживается заметная доля ее влияния, которая образует причудливый синтез норм иудаизма и эллинистической практики. Однако нельзя не принимать во внимание и иные возможные причины. Например, нежелание усиливать позиции того или иного рода Иудеи как гипотетического соперника за власть (что произошло во время восстания Птолемея, сына Авува, против Симона) или отсутствие более достойных кандидатур с соответствующей сакральной чистотой крови. Последнее относит нас к запретам, связанным с социально-правовым статусом жениха и невесты.

Этот статус определялся скорее чистотой крови и соотнесением с нормами иудаизма, нежели иными, прежде всего имущественными, характеристиками. Подтверждением важности подобного статуса могут служить два примера. Первый связан с Александром Яннаем, мать которого, согласно преданию, во время беременности была краткий период времени в заточении, что позволило врагам иудейского царя объявить его сыном наложницы, что автоматически должно 
было лишить его статуса первосвященника. Конфликт, вызванный этими событиями, лег в основу восстания фарисеев 92-86 гг. до н.э., жестко подавленного Яннаем (AJ XIII:13,5). Вторым примером может служить брак Ирода и Мариам в 37 г. до н.э. Даже с учетом того насыщенного внешне- и внутриполитического контекста, окружавшего этот брак, важным было то, что Мариам относилась к роду первосвященника, что налагало жесткие ограничения на возможную партию (AJ XIV:12,1). Однако Ирод, который хоть и не был иудеем, был идумеянином, который, согласно нормам Танаха, соответствовал критериям ритуальной чистоты брака (Втор 23:7) ${ }^{10}$.

Иосиф Флавий, главный источник по истории Хасмонейского государства, к слову, соотносивший себя с родом Хасмонеев, особо подчеркивал «благородство, статность и красоту» Александра и Мариам (внуков и Аристобула II, и Гиркана II), которые были плодом кровнородственного внутридинастического брачного союза. По его словам, это было признаком родовитого происхождения (AJ XV:2,5-6; 3,3).

Так или иначе, династическая политика Хасмонеев отличалась ярко выраженным консерватизмом, и все брачные запреты, связанные с нормами иудаизма, соблюдались неукоснительно. Это очень сильно ограничивало политику государства Хасмонеев, так как лишало ее традиционно сильного метода внешнеполитической активности. Мы не имеем фактов, демонстрирующих наличие династических связей правящей династии с представителями других монархий

${ }^{10}$ Брачная политика Ирода и Иродиадов исключительно интересна и заслуживает отдельного исследования. В контексте настоящей статьи, впрочем, сравнение не будет достаточно уместным в силу принципиального момента - принадлежности Хасмонеев к роду первосвященников, что было важной частью проводимой ими династической политики. Действия Ирода сильно отличаются от хасмонейских. Наиболее ярко это различие проявляется на примере Саломеи, сестры Ирода. Она была первоначально замужем за Костобаром, с которым развелась вопреки иудейской традиции (AJ XV:7,9-10), а затем была сосватана за наббатейского вельможу Силлая, впрочем, брак не состоялся, так как он отказался переходить в иудаизм, что было важным для Ирода (AJ XVI:7,6). Таким образом, только на примере сестры Ирода можно увидеть, что брачная политика идумеянина строилась на схожих, но несколько отличающихся принципах. Принадлежность к иудаизму остается важным пунктом, а вот социальный статус, этническая принадлежность и детальное следование всем нормам иудаизма не играют ведущей роли, уступая место политической конъюнктуре и личным амбициям и желаниям правителя. Последний момент ярко проявляется в многочисленных браках самого Ирода. 
эллинистического мира. При этом даже с учетом лакун в источниках логичным представляется факт укрепления положения династии с помощью браков с представителями господствующего общества Иудеи, по крайней мере, на раннем этапе, когда статус новой династии не был подкреплен реальной властью в виде наемных войск и политического статуса царей Иудеи.

В завершении стоит суммировать, что принадлежность к роду первосвященников накладывала серьезные ограничения на брачные союзы. Вместе с тем роль правителей государства неизбежно требовала использования брака как важного элемента внутри- и внешнеполитической стабильности государства.

При первых правителях Хасмонеях (до Симона Маккавея включительно) заключаются брачные союзы с представителями иудейской элиты, направленные на укрепление позиции новой династии среди господствующего общества Иудеи. Наиболее вероятно, что и впоследствии жены правителей Хасмонеев, о которых в источниках чрезвычайно мало информации, также были из числа представителей родов, относящихся к иудейской элите. Однако в дальнейшем, после Александры Саломеи, эта ситуация меняется.

При последних правителях независимой Иудеи можно наблюдать начало заключения близкородственных браков. Данное явление исключительно интересно при соотнесении с общеэллинистической парадигмой, где подобное было нормальным элементом брачной политики правящей династии. Невозможность заключения браков с неиудеями вполне объяснима религиозными запретами. Однако переход от браков с представителями местной элиты к близкородственным бракам не вполне ясен и определяем одним лишь традиционным обращением к иудаизму Второго Храма. В этой связи объяснением может послужить позиция, определяющая Хасмонеев как монархов эллинизированных и довольно прагматично применяющих некоторые общеэллинистические практики, не запрещенные нормами иудаизма.

Таким образом, анализ брачной политики и запретов в ней позволяет глубже изучить господствующее общество Иудеи, а также прояснить степень эллинизированности иудейских правителей из династии Хасмонеев. Она, очевидно, носила активный, но избирательный характер, регулируясь политикой правящей династии и соображениями соответствия статусу первосвященнического рода. 
Литература и источники

Габелко 2006 - Габелко О.Л. Анатолийское этнополитическое койне и особенности эллинизма в Малой Азии (на примере Вифинского царства): Дис. на соискание уч. ст. д-ра ист. наук: 07.00.03. Казань, 2006.

Григер 2008 - Григер М.В. Семья и брак в еврейской общине палестины II-III вв. н.э. Дис. на соискание уч. ст. канд. ист. наук: 07.00.03. Казань, 2008.

Каранаев 2015 - Каранаев М.Н. Армия и военная политика государства Хасмонеев. Дис. на соискание уч. ст. канд. ист. наук. Казань, 2015.

Ковельман, Гершович 2014 - Ковельман А., Гершович У. Священный брак в Мишне и Бавли Киддушин // Круг жизни в славянской и еврейской культурной традиции / Отв. ред. О.В. Белова. М., 2014. С. 9-19.

Atkinson 2008 - Atkinson K. The Salome No One Knows: Long-time Ruler of a Prosperous and Peaceful Judea Mentioned in Dead Sea Scrolls // Biblical Archaeology Review. 2008. Vol. 34. P. 60-65, 72-73.

Gera 1990 - Gera D. On the Credibility of the History of the Tobiads // Greece and Rome in Eretz Israel: collected essays / Ed. by A. Kasher, U. Rappaport, G. Fux. Jerusalem, 1990. P. 21-38.

Ilan 1995 - Ilan T. The Attraction of Aristocratic Women to Pharisaism during the Second Temple Period // The Harvard Theological Review. Cambridge (MA). 1995. Vol. 88. № 1. P. 1-33.

Ilan 2001 - Ilan T. Shelamzion in Qumran: New Insights // Historical Perspectives: From the Hasmoneans to Bar Kokhba in Light of the Dead Sea Scrolls / Ed. by David Goodblatt, Avital Pinnick, Daniel R. Schwartz. Leiden, 2001. P. 57-68.

Ilan 2006 - Ilan T. Silencing the Queen: The Literary Histories of Shelamzion and Other Jewish Women. Tübingen, 2006.

Ma 2004 - Ma J. Les rois // Le Monde hellénistique. Espaces, sociétés, cultures 32331 av. JC / Sous la direction de A. Erskine. Rennes, 2004. P. 254-255.

Mazar 1957 - Mazar B. The Tobiads // Israel Exploration Journal. 1957. Vol. 7. № 3. P. 137-145.

Moor 1932 - Moor G.F. Judaism in the first centuries of the Christian era. The age of the Tannaim. Vol. II. Cambridge, 1932.

Noegel 2006 - Noegel S.B. The Lachish Ostraca // The Ancient Near East: Historical Sources in Translation / Ed. by Mark W. Chavalas. London, 2006. P. 400-403.

Ogden 1999 - Ogden D. Polygamy, Prostitutes and Death. The Hellenistic Dynasties. London; Swansea, 1999.

Satlow 2001 - Satlow M. Jewish Marriage in Antiquity. Princenton, 2001.

Schwartz 2002 - Schwartz D.R. Once Again on Tobiad Chronology: Should We Let a Stated Anomaly be Anomalous? A Response to Gideon Fuks // Journal of Jewish Studies. 2002. Vol. 53. Iss. 1. P. 146-151. 
Seibert 1967 - Seibert J. Historische Beiträge zu den Dynastischen Verbindungen in hellenistischer Zeit. Wiesbaden, 1967. S. 129-131.

Zeitlin 1932-1933 - Zeitlin S. The Tobias Family and the Hasmoneans: A Historical Study in the Political and Economic Life of the Jews of the Hellenistic Period // Proceedings of the American Academy for Jewish Research. 1932-1933. Vol. 4. P. 169-223.

\section{Marriage Prohibitions in the Hasmoneans' Dynastic Politics}

\section{Mikhail Karanaev}

(Nizhnekamsk Institute of Chemical Technology, Nizhnekamsk, Russia)

PhD in History, ORCID ID : 0000-0001-9342-7078,

Associate Professor, Department of Humanities, Nizhnekamsk Institute of Chemical Technology (branch) Federal State Educational Institution of Higher Education «Kazan National Research Technological University» (Nizhnekamsk), 423578, 47 Stroiteley str., Nizhnekamsk, Russia, tel.: +7 (8555) 39-23-87,

E-mail: karanaevmk@mail.ru

Summary: The article describes the marriage prohibitions in the Hasmonean state's dynastic policy (II-I centuries BC). The Jewish rulers had a very strict approach in choosing a partner. The main criteria were ritual purity and good origin (by the Judaic norms), as well as belonging to the Jewish elite. During the last rulers of an independent state of the Hasmoneans (Aristobul II and Hyrkanus II) there was a transition to consanguineous marriages. One of the reasons is the influence of the Hellenistic tradition, in which such marriages are normal. In Judaism there are prohibitions on incest, but the Hasmoneans were able to meet the standards of Judaism (marriage with a cousin). Such a policy is an excellent example of the specificity of the Hasmonean dynasty: to follow the norms of Judaism, while being in the context of the common Hellenistic paradigm.

Keywords: Judea, Judaism, Hasmonean State, Hellenism, marriage prohibitions 


\section{References}

Atkinson K. The Salome No One Knows: Long-time Ruler of a Prosperous and Peaceful Judea Mentioned in Dead Sea Scrolls // Biblical Archaeology Review. 2008. Vol. 34. P. 60-65, 72-73.

Gera D. On the Credibility of the History of the Tobiads // Greece and Rome in Eretz Israel: collected essays / Ed. by A. Kasher, U. Rappaport, G. Fux. Jerusalem, 1990. P. 21-38.

Ilan T. The Attraction of Aristocratic Women to Pharisaism during the Second Temple Period // The Harvard Theological Review. Cambridge (MA). 1995. Vol. 88. № 1. P. 1-33.

Ilan T. Shelamzion in Qumran: New Insights // Historical Perspectives: From the Hasmoneans to Bar Kokhba in Light of the Dead Sea Scrolls / Ed. by David Goodblatt, Avital Pinnick, Daniel R. Schwartz. Leiden, 2001. P. 57-68.

Ilan T. Silencing the Queen: The Literary Histories of Shelamzion and Other Jewish Women. Tübingen, 2006.

Kovelman A., Gershovich U. Sviashchennyı̌ brak v Mishne i Bavli Kiddushin // Krug zhizni v slavianskoĭ i evrěskoĭ kulturnoĭ traditsii / Ed. by O.V. Belova. Moscow, 2014. P. 9-19.

Ma J. Les rois // Le Monde hellénistique. Espaces, sociétés, cultures 323-31 av. JC / Sous la direction de A. Erskine. Rennes, 2004. P. 254-255.

Mazar B. The Tobiads // Israel Exploration Journal. 1957. Vol. 7. № 3. P. 137-145.

Moor G.F. Judaism in the first centuries of the Christian era. The age of the Tannaim.

Vol. II. Cambridge, 1932.

Noegel S.B. The Lachish Ostraca // The Ancient Near East: Historical Sources in Translation / Ed. by Mark W. Chavalas. London, 2006. P. 400-403.

Ogden D. Polygamy, Prostitutes and Death. The Hellenistic Dynasties. London; Swansea, 1999.

Satlow M. Jewish Marriage in Antiquity. Princenton, 2001.

Schwartz D.R. Once Again on Tobiad Chronology: Should We Let a Stated Anomaly be Anomalous? A Response to Gideon Fuks // Journal of Jewish Studies. 2002. Vol. 53. Iss. 1. P. 146-151.

Seibert J. Historische Beiträge zu den Dynastischen Verbindungen in hellenistischer Zeit. Wiesbaden, 1967. S. 129-131.

Zeitlin S. The Tobias Family and the Hasmoneans: A Historical Study in the Political and Economic Life of the Jews of the Hellenistic Period // Proceedings of the American Academy for Jewish Research. 1932-1933. Vol. 4. P. 169-223. 